Notes

\title{
Analysis of Phosphorus-containing Amino Acid-type Herbicides by Sheathless Capillary Electrophoresis/Electrospray Ionization-Mass Spectrometry Using a High Sensitivity Porous Sprayer
}

\author{
Mio KaWaI,* Yoshiaki Iwamuro,* Reiko IIo-Ishimaru,* Satoshi Chinaka, *† Nariaki Takayama,* \\ and Kazuichi HAYAKAWA**
}

*Forensic Science Laboratory, Ishikawa Prefectural Police Headquarters, 1-1 Kuratsuki,

Kanazawa 920-8553, Japan

**Institute of Medical, Pharmaceutical and Health Sciences, Kanazawa University, Kakuma,

Kanazawa 920-1192, Japan

\begin{abstract}
We describe a new practical capillary electrophoresis/electrospray ionization-mass spectrometry (CE/ESI-MS) method for the forensic analysis of phosphorus-containing amino acid-type herbicides, glyphosate (GLYP), glufosinate (GLUF) and bialaphos (BIAL). A new sheathless interface, a high sensitivity porous sprayer (HSPS), was used in this study. The limits of detections of GLYP, GLUF and BIAL were 7.6, 0.61 and $0.57 \mathrm{pg}$, respectively. These values were $4-36$ times lower than these obtained by conventional CE/ESI-MS using a sheath liquid. The developed method was successfully applied to the analysis of beverages spiked with the herbicides.
\end{abstract}

(Received April 17, 2011; Accepted June 20, 2011; Published August 10, 2011)

\section{Introduction}

Phosphorus-containing amino acid-type herbicides, such as glyphosate (GLYP), glufosinate (GLUF) and bialaphos (BIAL) (Fig. 1), are widely used and easy to obtain in Japan. There have been criminal cases in which these herbicides have been added to beverages maliciously. The acute toxicity of the herbicides is not high. ${ }^{1,2} \mathrm{LD}_{50}$ for male rats is in the range from $268 \mathrm{mg} / \mathrm{kg}$ (BIAL) to $6250 \mathrm{mg} / \mathrm{kg}$ (GLYP). ${ }^{2}$ However there
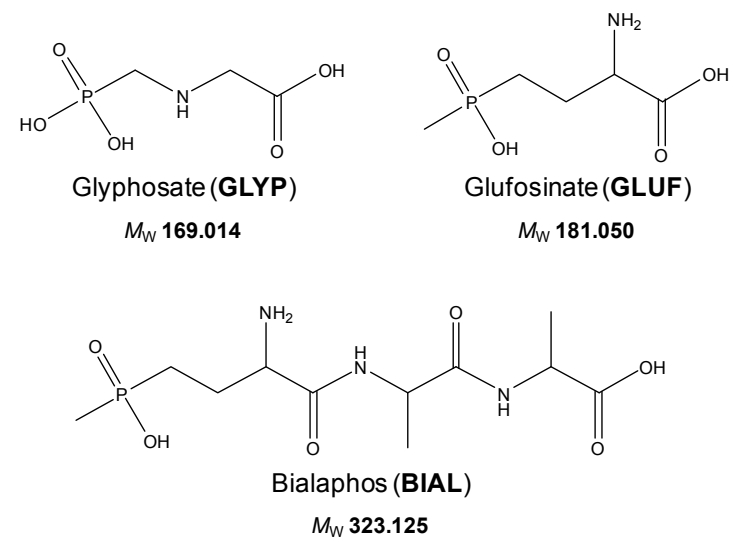

Fig. 1 Structures of phosphorus-containing amino acid-type herbicides.

\footnotetext{
$\dagger$ To whom correspondence should be addressed.
}

E-mail: chem@chinaka.jp have been several dozen fatal (suicide) cases every year in which commercial formulations of the herbicides have been taken. $^{3}$ Therefore, a rapid and reliable analytical method for the herbicides in beverages is needed.

We previously reported a method that couples capillary electrophoresis (CE) with UV-absorption for GLYP analysis using online copper(II)-GLYP derivatization and successfully detected GLYP in tea beverage samples. ${ }^{4}$ Subsequently, we developed a CE/electrospray ionization-mass spectrometry (CE/ESI-MS) method using a chemically modified capillary under acidic conditions for a rapid and reproducible analysis of these herbicides. ${ }^{5}$ In this report, we describe a sheathless CE/ESI-MS method using a high sensitivity porous sprayer (HSPS) for the forensic analysis of phosphorus-containing amino acid-type herbicides and we compare the results with those obtained with CE/ESI-MS using a sheath liquid.

\section{Experimental}

Reagents and chemicals

GLYP, GLUF, BIAL and other chemicals were obtained from Wako Pure Chemicals (Osaka, Japan). Ultrapure water was provided by a Milli-RX12alpha and Milli-Q SP system (Millipore, Bedford, MA) and was used for all procedures.

\section{CE/ESI-MS systems}

Both the CE/ESI-MS and HSPS systems consisted of an MS Ready CE Prototype Capillary Electrophoresis System (Beckman Coulter, Brea, CA) and a micrOTOF II mass spectrometer (Bruker Daltonics, Bremen, Germany). 


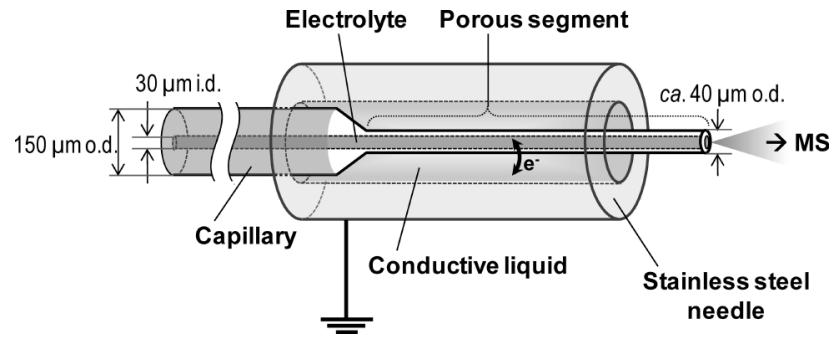

Fig. 2 Structure of the HSPS.

\section{Sheathless CE/ESI-MS}

A prototype HSPS (Fig. 2) provided by Beckman Coulter was used. The separation capillary (fused-silica capillary, $30 \mu \mathrm{m}$ i.d./150 $\mu \mathrm{m}$ o.d., $90 \mathrm{~cm}$ length) had a porous segment at its outlet side. The porous segment was surrounded by a stainlesssteel needle that was filled with a conductive liquid and that made electrical contact possible between the electrolyte and the conductive liquid. A nano ESI source (Bruker Daltonics) was used for the MS inlet. The background electrolyte (BGE) was $50 \mathrm{mM}$ formic acid adjusted to $\mathrm{pH} 10.0$ with $50 \mathrm{mM}$ ammonia. The conductive liquid was the same as BGE in this study.

A new capillary was conditioned with liquids in the order: methanol, water, $0.1 \mathrm{~N} \mathrm{HCl}$, water, $0.1 \mathrm{~N} \mathrm{NaOH}$, water and BGE. The stainless-steel needle was filled with a conductive liquid. The HSPS was set on an $x-y-z$ stage. The distance between the MS inlet and the end of HSPS capillary was optimized by maximizing the signals of test compounds under continuous electrophoresis. Between runs, the capillary was rinsed for $3 \mathrm{~min}$ at $50 \mathrm{psi}$ with $\mathrm{BGE}$ and the stainless-steel was refilled with $\mathrm{BGE}$ for $1 \mathrm{~min}$ at 5 psi. A sample solution was injected for $10 \mathrm{~s}$ at $5 \mathrm{psi}(7.6 \mathrm{~nL})$. The power supply was operated in the constant-voltage mode at $+30 \mathrm{kV}$. After separations, the calibrant for the mass spectrometer (sodium formate; $0.1 \%$ formic acid $/ 10 \mathrm{mM}$ sodium hydrate $/ 50 \%$ acetonitrile (1/1/1)) was introduced into the capillary for $1 \mathrm{~min}$ at 5 psi. BGE was then introduced for 3 min at 50 psi (this step was the same as the rinse step in sequence analysis).

MS conditions were as follows: ESI was conducted in the positive ion mode and the capillary voltage was $-1650 \mathrm{~V}$. The capillary exit voltage and the hexapole radio frequency were set at $100 \mathrm{~V}$ and $80 \mathrm{Vpp}$, respectively.

\section{Sheath CE/ESI-MS}

Fused-silica capillaries of $30 \mu \mathrm{m}$ i.d./375 $\mu \mathrm{m}$ o.d. and $50 \mu \mathrm{m}$ i.d./375 $\mu \mathrm{m}$ o.d. (GL Sciences, Tokyo, Japan) were used as separation capillaries. Between runs, the capillary was rinsed for $3 \mathrm{~min}$ at $50 \mathrm{psi}$ with BGE. Each sample solution was injected at $5 \mathrm{psi}$ for $10 \mathrm{~s}(7.6 \mathrm{~nL})$ for $30 \mu \mathrm{m}$ i.d. capillary, and at 0.8 psi for $8 \mathrm{~s}(7.5 \mathrm{~nL})$ for $50 \mu \mathrm{m}$ i.d. capillary. The power supply was operated in the constant-voltage mode at $+30 \mathrm{kV}$.

A conventional CE ESI sprayer and a conventional ESI source (Bruker Daltonics) were used for the CE/ESI-MS interface. The sheath liquid was $10 \mathrm{mM}$ ammonium acetate/methanol (1/1, $\mathrm{v} / \mathrm{v}$ ) and was maintained at $4 \mu \mathrm{L} / \mathrm{min}$. The nebulizing nitrogen gas was set at 0.4 bar at operating and 0 bar at conditioning and injecting. ESI capillary voltage and end plate offset were -4500 and $-500 \mathrm{~V}$, respectively. Dry nitrogen gas was heated at $200^{\circ} \mathrm{C}$ and delivered at a flow rate of $4.0 \mathrm{~L} / \mathrm{min}$. Other parameters of MS conditions were followed by sheathless CE/ESI-MS with HSPS.

\section{Samples and pretreatment procedure}

Roundup $^{\circledR}$ (Nihon Monsant, Tokyo, Japan), Basta ${ }^{\circledR}$ (Bayer CropScience, Tokyo, Japan) and Kusanon ${ }^{\circledR}$ (Sumitomo Chemical Garden Products, Tokyo, Japan) were used as commercial formulations of GLYP, GLUF and BIAL, respectively. Roundup contains $41.0 \%$ GLYP isopropylamine salt, Basta contains $18.5 \%$ GLUF ammonium salt and Kusanon contains $0.4 \%$ BIAL sodium salt. Commercial beverages: green tea, grape juice and cola, were purchased from a local market. These herbicides were added in each of the three beverages to a concentration of $40 \mu \mathrm{g} / \mathrm{mL}$, individually. Each sample was diluted with water and filtered $(0.22 \mu \mathrm{m})$ before analysis.

\section{Results and Discussion}

\section{Optimization of sheathless CE/ESI-MS conditions}

Electroosmotic flow (EOF) is needed to maintain a stable electrospray state with the HSPS, because an electrolyte is essential for the electrospray at the MS interface. ${ }^{6-9}$ An untreated fused-silica capillary generates EOF at $\mathrm{pH} c a .3$ or higher and the EOF becomes faster with increasing $\mathrm{pH}$. The phosphorus-containing amino acid-type herbicides acquire a negative charge in weak acid to alkaline conditions. Then they move toward the inlet due to the force of the electric field in the inlet-positive mode. Therefore, the EOF should be faster than their electrophoretic mobilities to detect them. ${ }^{10-12}$

Combinations of formic acid with ammonia, diethylamine or ethylamine at various $\mathrm{pHs}$ and concentrations were examined. Migration times of GLYP, GLUF and BIAL were reasonably short and their peak shapes were better around $\mathrm{pH}$ 10. BGE composition that made the capillary current below $5 \mu \mathrm{A}$ was needed to maintain a stable electrophoresis state using the HSPS capillary; thus, higher concentrations could not be used. Therefore, the optimum BGE conditions were found to be $50 \mathrm{mM}$ formic acid-ammonia adjusted to $\mathrm{pH} 10.0$ with an applying voltage of $+30 \mathrm{kV}$ (this resulted in an electric current of $c a .3 \mu \mathrm{A}$ at $25^{\circ} \mathrm{C}$ ). Good performance was obtained with a conductive liquid which was of the same composition as the BGE.

\section{Comparison with sheath CE/ESI-MS}

A sheath CE/ESI-MS system requires a sheath liquid and nebulizing gas. Nebulizing gas makes a spray with the sheath liquid and BGE, while the sheath liquid provides electrical contact at the capillary end. The spray state is greatly affected by the shape and position of the capillary end in the sprayer. Thus, the operator must have considerable skill to get a stable spray. Moreover, analytes are continually diluted by the sheath liquid. On the other hand, a sheathless CE/ESI-MS system has a simple structure and is easy to use. The stable spray state was constantly obtained regardless of the shape of the capillary end, because the spray was made by the electrical suction force of the MS inlet. ${ }^{6}$

Limits of detection (LODs), linear ranges and relative standard deviations (RSDs) of migration time and peak area are shown in Table 1. LOD was determined not by signal-to-noise ratio but by whether or not a peak was actually detected, because no noise was detected at the MS range of $\pm 5 \mathrm{mDa}$. RSD was calculated by 5 replicate analyses in a day. In sheath CE/ESI-MS analyses, a $30-\mu \mathrm{m}$ i.d. or $50-\mu \mathrm{m}$ i.d. capillary is used as the separation capillary. The former has the same inside diameter as the HSPS capillary and the latter is commonly used on sheath CE/ESI-MS systems.

The LODs obtained by the sheathless CE/ESI-MS were 4 - 36 
Table $1 \quad$ LOD $^{\mathrm{a}}$, linear range ${ }^{\mathrm{b}}$ and RSD

\begin{tabular}{|c|c|c|c|c|c|c|c|c|c|c|c|c|}
\hline \multirow{3}{*}{ Compound } & \multicolumn{4}{|c|}{ Sheathless CE/ESI-MS } & \multicolumn{4}{|c|}{$\begin{array}{l}\text { Sheath CE/ESI-MS } \\
(30 \mu \mathrm{m} \text { i.d. capillary })\end{array}$} & \multicolumn{4}{|c|}{$\begin{array}{l}\text { Sheath CE/ESI-MS } \\
(50 \mu \mathrm{m} \text { i.d. capillary) }\end{array}$} \\
\hline & \multirow{2}{*}{$\begin{array}{c}\text { LOD/ } \\
\text { pg }\end{array}$} & \multirow{2}{*}{$\begin{array}{l}\text { Linear } \\
\text { range/ } \\
\mu \mathrm{g} \mathrm{\textrm {mL } ^ { - 1 }}\end{array}$} & \multicolumn{2}{|c|}{$\mathrm{RSD}, \%$} & \multirow{2}{*}{$\begin{array}{l}\text { LOD/ } \\
\text { pg }\end{array}$} & \multirow{2}{*}{$\begin{array}{l}\text { Linear } \\
\text { range/ } \\
\mu \mathrm{g} \mathrm{mL}^{-1}\end{array}$} & \multicolumn{2}{|c|}{$\mathrm{RSD}, \%$} & \multirow{2}{*}{$\begin{array}{l}\text { LOD/ } \\
\text { pg }\end{array}$} & \multirow{2}{*}{$\begin{array}{c}\text { Linear } \\
\text { range/ } \\
\mu \mathrm{g} \mathrm{mL}-1\end{array}$} & \multicolumn{2}{|c|}{ RSD, \% } \\
\hline & & & $\mathrm{PA}^{\mathrm{d}}$ & $\mathrm{Mt}^{\mathrm{e}}$ & & & $\mathrm{PA}^{\mathrm{d}}$ & $\mathrm{Mt}^{\mathrm{e}}$ & & & $\mathrm{PA}^{\mathrm{d}}$ & $\mathrm{Mt}^{\mathrm{e}}$ \\
\hline GLYP & 7.6 & $5-100$ & 9.60 & 0.87 & 44 & $10-1000$ & 6.29 & 0.86 & 75 & $50-1000$ & 7.07 & 0.82 \\
\hline GLUF & 0.61 & $0.1-50$ & 4.70 & 0.19 & 2.4 & $1-100$ & 6.19 & 0.69 & 7.2 & $5-500$ & 8.09 & 0.46 \\
\hline BIAL & 0.57 & $0.1-50$ & 4.80 & 0.32 & 2.7 & $1-100$ & 9.16 & 0.80 & 20 & $5-500$ & 6.13 & 0.60 \\
\hline
\end{tabular}

a. Limit of detection. b. Based on peak area $\left(r^{2}>0.990\right)$. c. Relative standard deviation of five replicate analyses of standard mixture $(50 \mu \mathrm{g} / \mathrm{mL}$ GLYP, $1 \mu \mathrm{g} / \mathrm{mL}$ GLUF and $1 \mu \mathrm{g} / \mathrm{mL}$ BIAL for the sheathless CE/ESI-MS; $100 \mu \mathrm{g} / \mathrm{mL}$ GLYP, $10 \mu \mathrm{g} / \mathrm{mL}$ GLUF and $10 \mu \mathrm{g} / \mathrm{mL}$ BIAL for the sheath CE/ESI-MS). d. Peak area. e. Migration time.

(a)

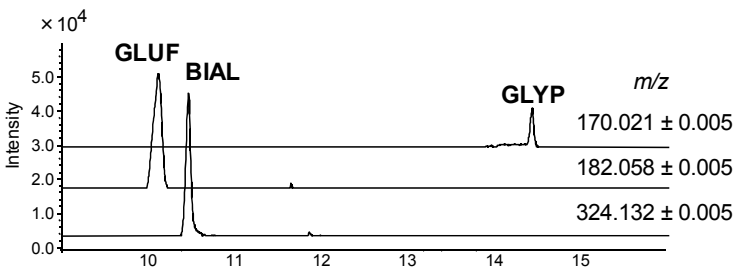

(b)

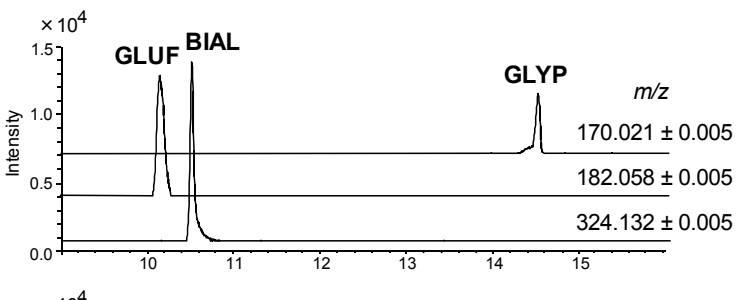

(c)

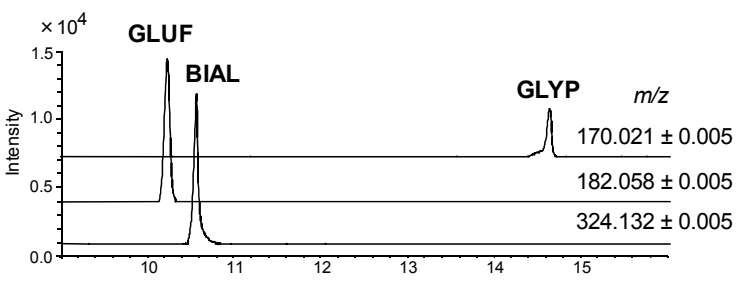

(d)

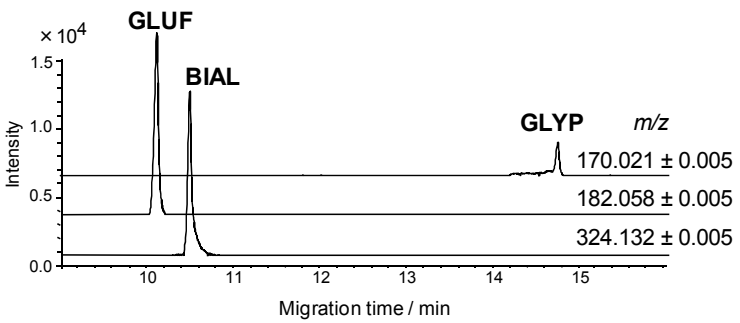

Fig. 3 Electropherograms of phosphorus-containing amino acid-type herbicides mixed with beverages. (a) Standard solution of GLYP, GLUF and BIAL (5 $\mu \mathrm{g} / \mathrm{mL}$ each). (b) Green tea, (c) grape juice and (d) cola spiked with commercial formulations of GLYP, GLUF and BIAL. The concentration of herbicides in each beverage was $40 \mu \mathrm{g} / \mathrm{mL}$, and the final concentration in each injected sample was $2 \mu \mathrm{g} / \mathrm{mL}$.

times lower than those obtained by the sheath CE/ESI-MS. This distinction means a difference of the concentration sensitivities, because the injection volume of each method was almost the same. The concentrations of the LODs of GLYP, GLUF and BIAL were $1.0,0.080$ and $0.075 \mu \mathrm{g} / \mathrm{mL}$, respectively. The proposed method has enough sensitivity for forensic samples such as beverages mixed with the herbicides. For the sheath
CE/MS, a $30-\mu \mathrm{m}$ i.d. capillary gave better sensitivity than a $50-\mu \mathrm{m}$ i.d. one. The peaks of the same compounds obtained by both capillaries had almost the same width; such a result indicated that the transfer efficiency to the MS of $30 \mu \mathrm{m}$ i.d. capillary was higher than that of $50 \mu \mathrm{m}$ i.d. one under the proposed analytical conditions. The within-day reproducibilities of the three methods were similar: the RSDs of the peak area ranged from 4.7 to $9.6 \%$, and those of the migration time ranged from 0.19 to $0.87 \%$. The between-day reproducibilities (RSDs) of peak area obtained by the proposed method were larger than $18 \%$, and those of migration time were also larger than $9.8 \%$. Therefore, a calibration curve should be made on the same day when quantifying an unknown sample.

\section{Analysis of real samples}

Three kinds of beverages: green tea, grape juice and cola, spiked with a mixture of three commercial formulations of herbicides were analyzed. Clear electropherograms were obtained only by dilution and filtration of the samples. A 20-fold dilution with water gave enough stacking effect (i.e., on-capillary sample concentration). The peaks of the three herbicides were clearly detected without interference of matrices (Fig. 3). The LODs of the compounds were almost the same as the LODs of standard solutions.

\section{Conclusions}

We have developed a method that combines sheathless CE/ESI-MS with HSPS for the forensic analysis of phosphorus-containing amino acid-type herbicides. This system was simple and easy to use. The sensitivity of the proposed method was higher than the sensitivities of conventional sheath CE/ESI-MS methods. The proposed method was successfully applied to the analysis of herbicides in beverages.

\section{Acknowledgements}

We sincerely thank Etsuo Arai and John C. Hudson (Beckman Coulter Inc.) for providing the HSPS devices and their appropriate pieces of advice.

\section{References}

1. Y. Hori and M. Fujisawa, in "Drugs and Poisons in Humans. A Handbook of Practical Analysis", ed. O. Suzuki and 
K. Watanabe, 2005, Springer, Berlin, 554.

2. The Pharmaceutical Society of Japan, "Yakudokubutsu Shikenho to Chukai 2006 (Standard Methods for Analysis in Poisoning with Commentary 2006, in Japanese)", 2006, Tokyo Kagaku Dojin, Tokyo, 267.

3. National Research Institute of Police Agency, "Annual Case Reports of Drug and Toxic Poisoning in Japan 2011 (in Japanese)", No. 53, 2011, Kashiwa, 78.

4. S. Kodama, Y. Ito, A. Taga, Y. Nomura, A. Yamamoto, S. Chinaka, K. Suzuki, T. Yamashita, T. Kemmei, and K. Hayakawa, J. Health Sci., 2008, 54, 602.

5. Y. Iwamuro, R. Iio-Ishimaru, S. Chinaka, N. Takayama, S. Kodama, and K. Hayakawa, J. Health Sci., 2010, 56, 606.

6. M. Moini, Anal. Chem., 2007, 79, 4241.
7. A. Nguyen and M. Moini, Anal. Chem., 2008, 80, 7169.

8. R. Haselberg, C. K. Ratnayake, G. J. de Jong, and G. W. Somsen, J. Chromatogr., A, 2010, 1217, 7605.

9. J. M. Busnel, B. Schoenmaker, R. Ramautar, A. Carrasco-Pancorbo, C. Ratnayake, J. S. Feitelson, J. D. Chapman, A. M. Deelder, and O. A. Mayboroda, Anal. Chem., 2010, 82, 9476.

10. L. Goodwin, J. R. Startin, B. J. Keely, and D. M. Goodall, J. Chromatogr., A, 2003, 1004, 107.

11. R. G. Wuilloud, M. Shah, S. S. Kannamkumarath, and J. C. Altamirano, Electrophoresis, 2005, 26, 1598.

12. G. Yang, X. Xu, M. Shen, W. Wang, L. Xu, G. Chen, and F. $\mathrm{Fu}$, Electrophoresis, 2009, 30, 1718. 